\title{
Anxiety and socio-economic status among healthy adults: the ATTICA Study
}

\section{Dear Editor:}

Throughout the past decade, several epidemiological and cross-cultural studies have provided important insight into the physical and psychological well-being of citizens throughout Europe (ESEMeD/MHEDEA 2000 Investigators, 2004; Wittchen \& Jacobi, 2005; Kessler \& Ustun, 2004). One of the psychological factors that has received special attention is anxiety (Tyrer \& Baldwin, 2006; Curran et al., 2006; Miller \& Massie, 2006; Somers et al., 2006), which has been associated with several chronic disorders, especially, coronary heart disease. Chronic anxiety may increase the risk of coronary heart disease by influencing various health behaviors, like smoking and unhealthy eating, promoting atherogenesis via increased risk of hypertension and promoting plaque rupture, coronary vasospasm, and thrombosis. Moreover, anxiety appears to be associated with abnormal cardiac autonomic control, which may indicate increased risk of fatal ventricular arrhythmias (Kubzansky et al., 1998). Due to economic, political, social and other cultural differences, the prevalence of anxiety across Europe and Americas appears to vary (Lieb et al., 2005. In addition, data regarding the epidemiology of anxiety and its determinants are lacking at population level, especially in southern European populations. Therefore, this paper seeks to provide a glimpse into the epidemiology of anxiety and related socio-demographic characteristics in a nationally representative sample of Greek adults (Pitsavos et al., 2003).

\section{METHODS}

\section{Population}

The "ATTICA" study (Pitsavos et al., 2003) is a health and nutrition survey conducted in the province of Attica, Greece. Seventy-eight percent of the participants currently reside in the city of Athens (urban) while $22 \%$ live in the areas surrounding the city (rural). To select participants, a random, multistage sampling method based on the age ( 5 stages), sex ( 2 stages) distribution of the Attica province according to the 2001 Census of the National Statistical Service of Greece was used. A total of 4056 residents were randomly identified for potential inclusion in this research. Individuals that did not have a cold or flu, acute respiratory infection, dental problems or surgery of any kind during the week preceding the study were asked to participate. A total of 1518 men and 1524 women consented (75\% participation rate); however, $5 \%$ of these men and $3 \%$ of these women were excluded from the present analyses due to clinical histories of cardiovascular disease. Psychological data were obtained from a sub sample of 853 participants (453 men, age $41 \pm 10$ y; 400 women, age $37 \pm 11$ y) based on the study's population according to the following algorithm: in each "block" (i.e., city-gender-age group) 1 in every 4 participants was randomly selected using a sequence of binary numbers (i.e., 1100101100). Therefore, this sub sample is representative of the population in this study as well as the general population of Greece, with only minor, insignificant differences in the age-sex distributions between the studied and target populations.

\section{MEASURES}

\section{Biochemical measurements}

Blood samples were taken from the antecubital vein after participants had fasted from food and alcohol for a minimum of 12 hours. The biochemical evaluations were conducted in accordance with the World Health Organization Lipid References Laboratories. Total-, high-density lipoprotein- (HDL), cholesterols, blood glucose and triglycerides were also measured in all participants, using colorimetric enzymic method in a Technicon automatic analyzer RA-1000 (Date-Behring Marburg GmbH Marburg, Germany). An internal quality control assessed the validity of cholesterol, triglycerides and HDL tests. The intra and inter-assay coefficients of variation of cholesterol and triglycerides levels did not exceed $4 \%$. 


\section{Socio-Demographic characteristics}

A standard demographic questionnaire was used to assess age, gender and marital status (i.e., married, divorced, widowed). Education levels were measured in the number of years in school. The mean annual income over the last three years was also recorded. Occupation status was assessed using a ten-point rating scale: unskilled occupations (e.g., hand workers) were assigned lower values; executive or skilled occupations (e.g., physicians, teachers, etc) were assigned higher values. An overall socio-economic status (SES) score was derived as a product of the aforementioned variables (i.e., years in school $\mathrm{X}$ mean annual income $\mathrm{X}$ occupational score). These data (range: $55,000-8,800,000$ ) were normally distributed according to the Kolmogorov-Smirnov criterion. Participants were then assigned to one of the SES tertiles based on their SES score with respect to this data distribution $\left(1^{\text {st }}\right.$ tertile: $<1,728,000 ; 2^{\text {nd }}$ tertile: $1,728,001-2,400,000 ; 3^{\text {rd }}$ tertile: $\left.>2,400,001\right)$.

\section{Lifestyle Characteristics}

Current smokers were defined as those who smoked at least one cigarette per day at the time of the study. Former smokers were defined as those who had stopped smoking, at least, one year before the study. All other participants were defined as non-smokers. Physical activity was defined as leisure-time activity of specified intensity ( $\mathrm{kcal} / \mathrm{min}$ expended) and duration (minutes per time), at least once per week during the past year. Participants who did not meet this criterion were considered physically inactive. Body Mass Index (BMI) scores were calculated as weight $(\mathrm{Kg})$ divided by standing height $\left(\mathrm{m}^{2}\right)$. Obesity was defined as body mass index $>29.9 \mathrm{Kg} / \mathrm{m}^{2}$ ).

\section{Clinical Characteristics}

Following the physical examinations (which required that participants be seated for, at least, 30 minutes), blood pressure was measured three times at the right arm (ELKA aneroid manometric sphygmometer, $\mathrm{Vn}$ Schielben Co., Munich, Germany). Participants whose average blood pressure levels were greater or equal to $140 / 90 \mathrm{mmHg}$, or were currently taking antihypertensive medication, were classified as hypertensive. Hypercholesterolemia was defined based on total serum cholesterol levels greater than $200 \mathrm{mg} / \mathrm{dl}$ or the use of lipid-lowering agents. Diabetes mellitus was defined as a blood sugar level greater than $125 \mathrm{mg} / \mathrm{dl}$ or the use of anti-diabetic medication(s).

\section{Dietary Characteristics}

Consumption of non-refined cereals and other similar products, vegetables, legumes, fruits, olive oil, dairy products, fish, beans, nuts, potatoes, eggs, sweets, poultry, red meat and meat products were measured on average-per-week during the past year through a validated food-frequency questionnaire from the Unit of Nutrition at the University of Athens Medical School (Katsouyanni et al., 1997). Frequency of consumption was approximated using the number of times per month each food was consumed. Alcohol consumption was measured in terms of daily ethanol intake (one $100 \mathrm{ml}$ wine glass as $12 \%$ ethanol concentration). Based on the Mediterranean Diet Pyramid (Panagiotakos et al., 2006), diet scores were calculated based on the degree adherence to they this dietary pattern. Higher values indicate closer adherence to the traditional Mediterranean diet.

\section{Psychological Assessment}

\section{Anxiety}

The 20-item, self-report State-Trait Anxiety Inventory (STAI), state version was used to asses current levels of anxiety symptomatology (Spielberger et al., 1970). The Greek translation of this assessment, which has been found reliable, was used in the research (Fountaoulakis $e t$ al., 2006). Participants responded to each of items with a frequency rating according to the following scale: 1never, 2 - sometimes, 3 - often, 4 - always. Total scores were based on the summation of the values assigned to each response (range: $20-80$ ). According to Spielberger's criteria, a score of 40 or higher reflects clinically relevant symptoms of anxiety. Although this specific cut-off has not been validated in a Greek population, the Greek STAI scale has been shown to have similar psychometric properties to other translations used in the international research (Fountaoulakis et al., 2006).

\section{Depression}

Due to the high correlation of depression and anxiety, the Zung Self-Rating Depression Scale (ZDRS) (Zung, $1965 ; 1990$ ) was also used in this work. The ZDRS is a self-report test designed to quickly and easily quantify the presence and severity of depressive symptomatology and was applied an all 853 participants. 


\section{D.B. Panagiotakos et al.}

\section{Statistical Analysis}

Continuous variables are presented as mean values standard deviation, while categorical variables are presented as absolute and relative frequencies. A multiadjusted regression analysis was applied in order to test the associations between various variables and the STAI score (outcome), after controlling for various characteristics of the participants. All reported p-values are based on two-sided tests and compared to a significance level of $5 \%$. Due to multiple comparisons performed we used the Bonferroni correction rule in order to account for the increase in Type I error. SPSS 14.0 software (SPSS Inc. 2004, Chicago, Illinois, USA) was used for all the statistical calculations.

\section{RESULTS}

Table I presents the basic characteristics of the study's participants by sex. Higher percentages of men than women smoke $(\mathrm{p}<0.001)$, have hypertension $(\mathrm{p}<0.001)$ and/or diabetes $(p<0.05)$. Men also tend to have higher BMI scores than women $(\mathrm{p}<0.001)$. Moreover, a difference was observed between sex and the distribution of SES groups (Table II). In particular, the lowest SES class contained significantly more men than women. The average STAI score across all participants is $41.1 \pm 11.9$. Women report higher levels of anxiety than men (Table 2 ); however, this difference is only significant in the 3544 years-of-age bracket $(\mathrm{p}<0.05)$. In accordance with Spielberger's criteria (i.e., STAI score 40 ), $55.2 \%$ of the woman and $50 \%$ of the men indicate clinically relevant symptoms of anxiety $(p=0.08)$. Furthermore, STAI score was not correlated with age, BMI, and smoking habits of the participants (all p-values $>0.15$ ).

Participants classified into the highest SES group have significantly lower STAI score than those in the middle or lower SES groups $(39 \pm 10$ vs. $43 \pm 12$ vs. $46 \pm 14$, respectively, $\mathrm{p}<0.001)$. Moreover, the difference observed between the lowest and middle SES groups is

Table I. - Characteristics of the study's participants.

\begin{tabular}{|c|c|c|c|}
\hline & $\operatorname{Men}(n=453)$ & Women $(n=400)$ & $\mathbf{P}$ \\
\hline Age (years) & $45 \quad 13$ & $44 \quad 18$ & 0.09 \\
\hline Current or former smoker $(\%)$ & $65 \%$ & $50 \%$ & $<0.001$ \\
\hline Body mass index $\left(\mathrm{Kg} / \mathrm{m}^{2}\right)$ & 27.35 .2 & 23.16 .0 & 0.23 \\
\hline Sedentary life (\%) & $58 \%$ & $61 \%$ & 0.11 \\
\hline Hypertension (\%) & $29 \%$ & $20 \%$ & 0.03 \\
\hline Hypercholesterolemia (\%) & $29 \%$ & $26 \%$ & 0.08 \\
\hline Diabetes mellitus (\%) & $5 \%$ & $4 \%$ & 0.18 \\
\hline Education level (years of school) & $13 \quad 3.4$ & 132.7 & 0.41 \\
\hline Mean annual income $\left(\times 10^{3} €\right)$ & 14.14 .6 & 12.46 .4 & 0.001 \\
\hline Occupational score $(0-10)$ & 7.42 .2 & 8.32 .5 & 0.01 \\
\hline Socio-economic status & & & $<0.001$ \\
\hline $\operatorname{Low}(\%)$ & $29 \%$ & $13 \%$ & \\
\hline Middle (\%) & $33 \%$ & $33 \%$ & \\
\hline $\operatorname{High}(\%)$ & $38 \%$ & $54 \%$ & \\
\hline Anxiety score (STAI) (20-80) & 401 & 4310 & 0.04 \\
\hline Depression score (ZDRS) $(20-80)$ & 4310 & 479 & $<0.001$ \\
\hline
\end{tabular}

Table II. - Mea (standard deviation) STAI score by age-sex group.

\begin{tabular}{lcccc}
\hline & Men & Women & P \\
\hline Age & & & & $<0.001$ \\
\hline & $<35$ years & $40.3 \pm 12.2$ & $41.5 \pm 11.4$ & 0.43 \\
\hline & $35-44$ years & $40.0 \pm 10.9$ & $42.3 \pm 12.9$ & 0.03 \\
\hline & $45-54$ years & $41.1 \pm 12.1$ & $41.0 \pm 12.0$ & 0.99 \\
\hline Overall & $55+$ & $42.7 \pm 11.1$ & $47.1 \pm 12.6$ & 0.19 \\
\hline
\end{tabular}


not significant $(\mathrm{p}=0.12)$. Furthermore, depression is highly associated with anxiety in both men and women ( $r$ $=0.52, \mathrm{r}=0.53$, respectively, $\mathrm{p}<0.001$ ). Even after adjusting for age, sex and ZDRS, STAI scores still differed significantly between the SES classes (adjusted mean values: $38 \pm 9$ vs. $43 \pm 11$ vs. $45 \pm 12$, $\mathrm{p}<0.001$ ). When stratified according to age, similar differences were also observed in each of the age brackets with the exception of the oldest participants (i.e., $>55$ years of age). In other words, anxiety scores differ among participants of varying SES statuses across all age groups, except for those older than 55 where no difference was observed $(\mathrm{p}=$ 0.52). Age-sex adjusted partial correlations between each of the components of the SES score (i.e., years of school, financial status, and occupational skills) and STAI reveal strongly significant inverse relationships ( $r$ for STAIyears of school $=-0.24, \mathrm{p}<0.001, r$ for STAI-income $=$ -
$0.19, \mathrm{p}<0.001$, and $\mathrm{r}$ for STAI-occupation skills $=-0.16$, $\mathrm{p}<0.001$ ). However, the correlation between occupational skills and STAI score is not significant in the $>35$ years of age bracket $(\mathrm{p}=0.10)$.

It is known that multiple comparisons are prone to bias, due to the increased probability of committing a type I error (i.e., false positive results). Thus, a multi-adjusted analysis was performed. Table III presents the multiple regression analyses between anxiety status (STAI score as dependent outcome) and other, related variables. Compared to the high SES group, participants of middle to lower SES status had increased levels of anxiety, after adjusting for age, sex, physical activity status, smoking and dietary habits, marital status and biological characteristics (Table III). Finally, depression also appears to be related to anxiety; however this association did not affect the relationship between SES and anxiety status.

Table III. - Results from multiple regression analysis that evaluated the association between anxiety status (STAI score, dependent outcome) and various explanatory variables.

\begin{tabular}{|c|c|c|c|c|}
\hline & & & Standard Error & $\mathbf{P}$ \\
\hline \multicolumn{5}{|l|}{ Socio-economic status } \\
\hline & Low vs. High & 8.33 & 1.44 & $<0.001$ \\
\hline & Middle vs. High & 5.34 & 0.88 & $<0.001$ \\
\hline Age (per 10-years) & & 0.02 & 0.05 & 0.64 \\
\hline Women vs. men & & -1.64 & 0.94 & 0.08 \\
\hline Sedentary vs. physically active & & -3.04 & 0.90 & 0.001 \\
\hline Depression score (per 1 unit) & & 0.83 & 0.48 & 0.001 \\
\hline Number of cigarettes smoked per day & & 0.04 & 0.88 & 0.97 \\
\hline Married vs. widowed, divorced, never married & & -7.40 & 4.31 & 0.12 \\
\hline Diet score (per 10 units) & & 0.01 & 0.04 & 0.68 \\
\hline Body mass index (per $1 \mathrm{~kg} / \mathrm{m}^{2}$ ) & & -0.03 & 0.12 & 0.77 \\
\hline Systolic blood pressure (per $1 \mathrm{mmHg}$ ) & & 0.01 & 0.04 & 0.80 \\
\hline Diastolic blood pressure (per $1 \mathrm{mmHg}$ ) & & 0.02 & 0.04 & 0.72 \\
\hline Glucose (per $1 \mathrm{mg} / \mathrm{dl}$ ) & & -0.01 & 0.02 & 0.73 \\
\hline Total cholesterol (per $1 \mathrm{mg} / \mathrm{dl}$ ) & & -0.02 & 0.01 & 0.19 \\
\hline
\end{tabular}

\section{DISCUSSION}

According to Spielberger's STAI scale and clinical criteria, a large proportion of Greek adults appear to exhibit clinically significant symptoms of anxiety. However, it is important to note that, although the Greek version of STAI scale has shown adequate psychometric comparability to other translations, the clinical cut-off has not yet been validated in a Greek population. Moreover, it was also observed from the present work that SES status appears to have a robust, inverse relation- ship to perceived anxiety, such that individuals in the highest SES groups indicate significantly lower symptoms of anxiety than those in the middle or lower SES groups. This association exists irrespective of depression status or several other potential confounders.

Although women tend to fare better than men in the physical domains assessed (e.g., fewer women smoke, have hypertension or diabetes than men), men tend to fare better than women psychologically (e.g., in levels of anxiety and depression) (Wittchen \& Jacobi, 2005; Tyrer \& Baldwin, 2006). In particular, women have reported 
higher levels of anxiety and depression than men (Table I), a trend which has been noted in several other studies [ESEMeD/MHEDEA 2000 Investigators, 2004; Lieb et al., 2005; Averina et al., 2005; Lloyd et al., 2003; Kessler et al., 2005; Robins et al., 1984). It is interesting to note that this gender effect is only significant in the 35-44 years-of-age bracket. This may be reflective of lifestyle differences (such as uneven distribution of child-rearing responsibilities, differing levels career stabilization) between men and women at this life stage. According to Spielberger's clinical criteria, $55 \%$ of women and $50 \%$ of men demonstrate symptoms of clinical anxiety. Taken together, these findings indicate that Greek women tend to experience higher anxiety than Greek men, both in terms of degree and prevalence.

The co-morbidity of anxiety with other choric illnesses, such as cancer, appears to be high. One recent study showed that as much as $34 \%$ of the chronically ill adults studied had been diagnosed with anxiety (Walke et al., 2007). Mores specifically, both depression and anxiety have been reported to play an aetiological role in the development of coronary heart disease (CHD) in 11 of 11 (i.e., $100 \%$ of the) prospective cohort studies considered in a systematic review (Hemingway \& Marmot, 1999). This report also cited six other studies, all of which indicated a prognostic role for both disorders in CHD (Hemingway \& Marmot, 1999). Based on this research, the association between anxiety and chronic illness appears certain. Socioeconomic status has been reported as an index of well-being, and a marker of health status (Schulz \& Northridge, 2004) work it was revealed that SES is inversely associated with perceived anxiety. Individuals in the highest SES group report significantly lower levels of anxiety than those in the middle or lowest SES groups (Table III). This is likely due to the fact that people of different social and economic statuses often experience different types "stressors". Individuals within the lowest SES group may have less stability at work or fewer career opportunities within their field. According to one study, individuals who have lower job control are at increased risk of cardiovascular disease (Bosma et al., 1997) reflected in the increased anxiety shown in lower SES groups. On the other hand, individuals with higher SES likely have increased stability at work, more opportunities for advancement within their jobs and fewer financial concerns. All of these factors likely contribute to the differences in perceived anxiety across SES groups. In line with this viewpoint the cognitive theory proposes that the experience of anxiety is modulated by the perception of the extent to which external factors will help (rescue factors) (Salkovskis \& Warwick, 2001).
Also note that the differences observed in anxiety across SES groups in our study are no longer significant in individuals of 55 years of age or older. This could be due to other lifestyle changes such as retirement (mean age of 60 years in Greece) or further stabilization of working status. Since, a growing body of evidence indicate that most psychiatric disorders other than dementia are less common in the elderly than among younger adults (Weissman, 2006) for the age-related changes found in the present study, one also could argue that symptoms of anxiety were mistakenly attributed to physical symptoms and/or cognitive impairments which become increasingly likely with advancing age (Jeste et al., 2005; Wittchen \& Jacobi, 2005; Rozanski \& Kubzansky, 2005). Another convincing explanation which does not exclude the above mentioned, but complement it, may be the issue of whether diagnostic instruments developed for younger age groups are appropriate for detecting symptoms of anxiety in elderly population whose life conditions are very different (Jeste et al., 2005).

Although Greece has experienced marked socio-economic development during the past decades, public debt, inflation and unemployment rates remain higher than the European Union average. This fact may partially explain the large proportion of people with STAI score higher than the clinical cut-off. Furthermore, among the variables that compose the developed SES score, the number of years of education appears to have the strongest inverse association with anxiety. The other two variables (i.e., income and occupational skills) likely reflect the unsystematic influence of several other variables and, therefore, are not as closely associated with anxiety as education. Education status reflects culture and has been strongly associated with cardiovascular disease risk, particularly via the increased prevalence of smoking habits, obesity and physical inactivity (Jacobsen, 1988; Pitsavos et al., 2002; Bonnet et al., 2005; Strawbridge et al., 2002). Moreover, education is strongly associated with income and occupation skills. Thus, it could be argued that years of school may mask the effect of the other SES components on anxiety scale. Finally, when controlling for other covariates (see Table III), anxiety is inversely related to physical activity and positively related to depression score. This finding is consistent with prior research which indicates that the degree of physical inactivity is associated with the severity of anxiety (de Girolamo et al., 2006). Two possible explanations include the lack of physical activity in anxious individuals may reflect decreased motivation to exercise and/or the lack of anxiety in physically active individuals may reflect the protective affects of exercise, which has also 
been shown in studies of depression. The correlation observed between anxiety and depression may reflect the interrelatedness among psychological variables in this population. As prior research has shown, depressive disorders and anxiety disorders often co-occur (Jacobsen, 1988). Because these variables are likely dependent in at some level, such a correlation can be expected.

\section{LIMITATIONS}

Due to the cross-sectional design of this study, causal interpretations cannot be made. Although the number of participants providing psychological information is much smaller than the total sample of the ATTICA study, the statistical power of the findings is maintained (82\% statistical power achieved per $10 \%$ difference in STAI scorer between SES groups at $\mathrm{p}<0.05$ ). Furthermore, it has been suggested that self reported questionnaires, like the STAI or the ZDRS, are supposed to be used as screening tools rather and not substitutes for an in-depth interview. The assessment of anxiety and depressive symptomatology using these questionnaires may not be so accurate and valid for detecting people with psychological disorders. Thus, the proportion of men and women that they were defined as having mild or severe anxiety may be under or over estimated by our study. Nevertheless, the observed associations between anxiety and SES may not be affected by the use of selfreported questionnaires.

\section{CONCLUSION}

Based on a large sample of adult men and women living in Greece, socio-economic status is inversely related to the degree of anxiety experienced, such that individuals that are higher than others on SES are lower than others on perceived anxiety. This finding may partially explain the higher burden of cardiovascular disease risk factors observed in people with lower socio-economic level observed in previous reports from the ATTICA study. Because social, political and economic factors play a large role in the psychosocial health of individuals, policy makers have the potential to play an active role in the primary prevention of psychological disorders around the world (Hemingway \& Marmot, 1999; de Girolamo et al., 2006). These associations should also be considered in future public health initiatives aimed at the reduction of anxiety and, consequently, the burden of related chronic diseases, across socio-economic strata.
Demosthenes B. Panagiotakos*

Christos Pitsavos** Efi Tsetsekou** Christina Chrysohoou** Mallory Kinlaw*

Charalabos Papageorgiou*** Constantin Soldatos***

Christodoulos Stefanadis**

*Department of Dietetics - Nutrition, 46 Paleon Polemiston St., 16674 Glyfada, Attica (Greece)

Fax: 302109600719

E-mail: d.b.panagiotakos@usa.net **First Department of Cardiology, School of Medicine, University of Athens, Athens (Greece) ***Department of Psychiatry, School of Medicine, University of Athens, Athens (Greece)

Declaration of Interest: None.

Received 29.06.07

Revised version received 28.07.07

Accepted on 30.07.07

\section{BIBLIOGRAFIA}

Averina M., Nilssen O., Brenn T., Brox J., Arkhipovsky V.L. \& Kalinin A.G. (2005). Social and lifestyle determinants of depression, anxiety, sleeping disorders and self-evaluated quality of life in Russia. Social Psychiatry and Psychiatric Epidemiology 40, 511-518.

Bonnet F., Irving K., Terra J., Nony P., Berthezène F. \& Moulin P. (2005).Anxiety and depression are associated with unhealthy lifestyle in patients at risk of cardiovascular disease. Atherosclerosis 178(2), 339-344.

Bosma H., Marmot M.G., Hemingway H., Nicholson A., Brunner E.J. \& Stansfeld S. (1997). Low job control and risk of coronary heart disease in the Whitehall II (prospective cohort) study. British Medical Journal 314, 558-565.

Curran J., Machin C. \& Gournay K. (2006). Cognitive behavioural therapy for patients with anxiety and depression. Nursing Standard 21 , 44-52.

de Girolamo G., Alonso J. \& Vilagut G. (2006). The ESEMeD-WMH project: strenghtening epidemiological research in Europe through the study of variation in prevalence estimates. Epidemiologia $e$ Psichiatria Sociale 15, 167-173.

ESEMeD/MHEDEA 2000 Investigators (2004). Prevalence of mental disorders in Europe: results from the European Study of the Epidemiology of Mental Disorders (ESEMeD) project. Acta Psychiatrica Scandinavica 109, Supplementum No. 1, 21-27.

Fountaoulakis K.N., Papadopoulou M., Kleanthous S., Papadoupoulou A., Bizeli V., Nimatoudis I., Iacovides A. \& Kaprinis G.S. (2006). Reliability and psychometric properties of the Greek translation of the Sate-Trate Anxiety Inventory form Y: Preliminary data. Annals of General Psychiatry 31(5), 2.

Hemingway H. \& Marmot M. (1999). Psychosocial factors in the aetiology and prognosis of coronary heart disease: systematic review of 


\section{D.B. Panagiotakos et al.}

prospective cohort studies. British Medical Journal 3(18), 1460 1467.

Jacobsen B.K. \& Thelle D.S. (1988). Risk factors for coronary heart disease and level of education. The Troms $ø$ heart study. American Journal of Epidemiology 127, 923-932.

Jeste D.V., Blazer D.G. \& First M. (2005). Aging-related diagnostic variations: need for diagnostic criteria appropriate for elderly psychiatric patients. Biological Psychiatry 58, 265-271.

Katsouyanni K., Rimm E.B., Gnardellis C., Trichopoulos D., Polychronopoulos E. \& Trichopoulou A. (1997). Reproducibility and relative validity of an extensive semi-quantitative food frequency questionnaire using dietary records and biochemical markers among Greek schoolteachers. International Journal of Epidemiology 26, Supplement 1, S118-127.

Kessler R.C. \& Ustun T.B. (2004). The World Mental Health (WMH) Survey Initiative Version of the World Health Organization (WHO) Composite International Diagnostic Interview (CIDI). International Journal of Methods in Psychiatric Research 13, 83-121.

Kessler R.C., Berglund P., Demler O., Jin R., Merikangas K.R. \& Walters E.E. (2005). Lifetime prevalence and age-of-onset distributions of DSM-IV disorders in the National Comorbidity Survey Replication. Archives of General Psychiatry 62, 593-602.

Kubzansky L.D., Kawachi I., Weiss S.T. \& Sparrow D. (1998). Anxiety and coronary heart disease: a synthesis of epidemiological, psychological, and experimental evidence. Annals of Behavioral Medicine $20,47-58$.

Lieb R., Becker E. \& Altamura C. (2005). Epidemiology of generalized anxiety disorder in Europe. European Neuropsychopharmacology $15,445-452$.

Lloyd C..E, Zgibor J., Wilson R.R., Barnett A.H., Dyer P.H. \& Orchard T.J. (2003). Cross-cultural comparisons of anxiety and depression in adults with type 1 diabetes. Diabetes/Metabolism Research and Reviews 19(5), 401-407.

Miller K. \& Massie M.J. (2006). Depression and anxiety. Cancer Journal 12, 388-397.

Panagiotakos D.B., Pitsavos C. \& Stefanadis C. (2006). Dietary patterns: a Mediterranean diet score and its relation to clinical and biological markers of cardiovascular disease risk. Nutrition, Metabolism and Cardiovascular Diseases 16, 559-568.

Pitsavos C., Panagiotakos D.B., Chrysohoou C., Skoumas J., Stefanadis C. \& Toutouzas P.K. (2002). Education and acute coronary syndromes: results from the CARDIO2000 epidemiological study. Bulletin of the World Health Organization 80(5), 371-377.
Pitsavos C., Panagiotakos D.B., Chrysohoou C., Stefanadis C. (2003). Epidemiology of Cardiovascular risk factors in Greece; aims, design and baseline characteristics of the ATTICA study. BMC Public Health 3(32), 1-9.

Robins L.N., Helzer J.E., Weissman M.M., Orvaschel H., Gruenberg E., Burke J.D. Jr \& Regier D.A. (1984). Lifetime prevalence of specific psychiatric disorders in 3 sites. Archives of General Psychiatry 41, 949-958.

Rozanski A. \& Kubzansky L.D. (2005). Psychologic functioning and physical health: a paradigm of flexibility. Psychosomatic Medicine 67, S47-53.

Salkovskis P. \& Warwick H. (2001). Meaning, misinterpretations, and medicine: A cognitive-Behavioral approach to understanding health anxiety and hypochondriasis. In Hypochondriasis: Modern Perspectives on an Ancient Malady (ed. V. Starcevic and D. Lipsitt D.), pp.202-222. Oxford University Press: Oxford.

Schulz A. \& Northridge M.E. (2004). Social determinants of health implications for environmental health promotion. Health Education \& Behavior 31, 455-471.

Somers J.M., Goldner E.M., Waraich P. \& Hsu L. (2006). Prevalence and incidence studies of anxiety disorders: a systematic review of the literature. Canadian Joumal of Psychiatry 51, 100-113.

Spielberger C.D., Gorsuch R.L. \& Lushene R.E. (1970). Manual for the State-trait Anxiety Inventory (STAI). Consulting Psychologists Press Inc: Palo Alto, CA.

Strawbridge W.J., Deleger S., Roberts R.E. \& Kaplan G. (2002). Physical activity reduces the risk of subsequent depression for older adults. American Journal of Epidemiology 156, 328-334.

Tyrer P. \& Baldwin D. (2006). Generalised anxiety disorder. Lancet $368,2156-2166$

Walke L.M., Byers A.L., Gallo W.T., Endrass J. \& Fried T.R. (2007). The Association of symptoms with health outcomes in chronically ill adults. Journal of Pain and Symptom Management 33(1), 58-66.

Weissman M.M. (2006). Recent advances in depression across the generations. Epidemiologia e Psichiatria Sociale 15, 16-19.

Wittchen H-U. \& Jacobi F. (2005). Size and burden of mental disorders in Europe. A critical review and appraisal of 27 studies. European Neuropsychopharmacology 15, 357-376.

Zung W. (1965). A self-rating depression scale. Archives of General Psychiatry 12, 63-70.

Zung W. (1990). The role of rating scales in the identification and management of the depressed patient in the primary care setting. Journal of Clinical Psychiatry 51, 72-76. 